\title{
From Monovalent to Multivalent Vaccines, the Exploration for Potential Preventive Strategies Against Hand, Foot, and Mouth Disease (HFMD)
}

\author{
Xiangchuan $\mathrm{He}^{1} \cdot$ Miaomiao $\mathrm{Zhang}^{1} \cdot$ Chen Zhao $^{1} \cdot$ Peiyong Zheng ${ }^{2} \cdot$ Xiaoyan Zhang $^{1}$ (D) Jianqing $\mathrm{Xu}^{1}$ (I)
}

Received: 22 April 2020 / Accepted: 25 August 2020/Published online: 30 September 2020

(C) Wuhan Institute of Virology, CAS 2020

\begin{abstract}
Hand, foot, and mouth disease (HFMD) recently emerged as a global public threat. The licensure of inactivated enterovirus A71 (EV-A71) vaccine was the first step in using a vaccine to control HFMD. New challenges arise from changes in the pathogen spectrum while vaccines directed against other common serotypes are in the preclinical stage. The mission of a broad-spectrum prevention strategy clearly favors multivalent vaccines. The development of multivalent vaccines was attempted via the simple combination of potent monovalent vaccines or the construction of chimeric vaccines comprised of epitopes derived from different virus serotypes. The present review summarizes recent advances in HFMD vaccine development and discusses the next steps toward a safe and effective HFMD vaccine that is capable of establishing a crossprotective antibody response.
\end{abstract}

Keywords Hand, foot, and mouth disease (HFMD) · Inactivated whole virus vaccine · Virus-like particles . Multivalent vaccines $\cdot$ Chimeric vaccines

\section{Introduction}

Human hand-foot-and-mouth disease (HFMD) caused several large outbreaks across the Asian-Pacific region, and it represents a global public health issue. Several viruses were identified as the primary HFMD-related pathogens, and this list includes enterovirus A71 (EV-A71), coxsackievirus A16 (CV-A16), CV-A6 and CV-A10, which all belong to the genus Enterovirus within the Picornaviridae family (Fang and Liu 2018). HFMD frequently occurs in children under five years old, and it is generally characterized by vesicular exanthema with self-limitation. There appears to be a link between the range of clinical

Jianqing Xu

xujianqing@shphc.org.cn

$\triangle$ Xiaoyan Zhang

zhangxiaoyan@shphc.org.cn

1 Shanghai Public Health Clinical Center and Institutes of Biomedical Science, Shanghai Medical College, Fudan University, Shanghai 201508, China

2 Longhua Hospital, Shanghai University of Traditional Chinese Medicine, Shanghai 200032, China manifestations and serotype differences, with some EVA71 infections resulting in severe complications, including brainstem encephalitis, aseptic meningitis, acute flaccid paralysis, cardiopulmonary failure, or death, but other serotypes generally showing mild symptoms (Lin et al. 2019). Historically, EV-A71 and CV-A16 primarily accounted for the global HFMD outbreaks; however, other serotypes are gradually gaining dominance due to the broad inoculation of and protection by inactivated EV-A71 vaccines. Indeed, CV-A6 displaced EV-A71 and CV-A16 as the predominant serotype in 2013 in Shanghai, and CVA10 has gradually become the dominating HFMD-related enterovirus (Song et al. 2017; Wang J et al. 2018; Bian et al. 2019).

Enteroviruses are positive-stranded RNA viruses with a genome size of approximately $7.4 \mathrm{~kb}$, which encodes a single polyprotein of $\sim 2100$ amino acids. The polyprotein is divided into three subregions, namely, P1, P2, and P3. The P1 region encodes four structural proteins (VP4VP2-VP3-VP1), and the $\mathrm{P} 2$ and $\mathrm{P} 3$ regions encode seven nonstructural proteins (P2-2A, 2B, 2C; P3-3A, 3B, 3C, 3D) (Fig. 1). The four structural proteins assemble to form the basic building block of the virion capsid, namely, a 


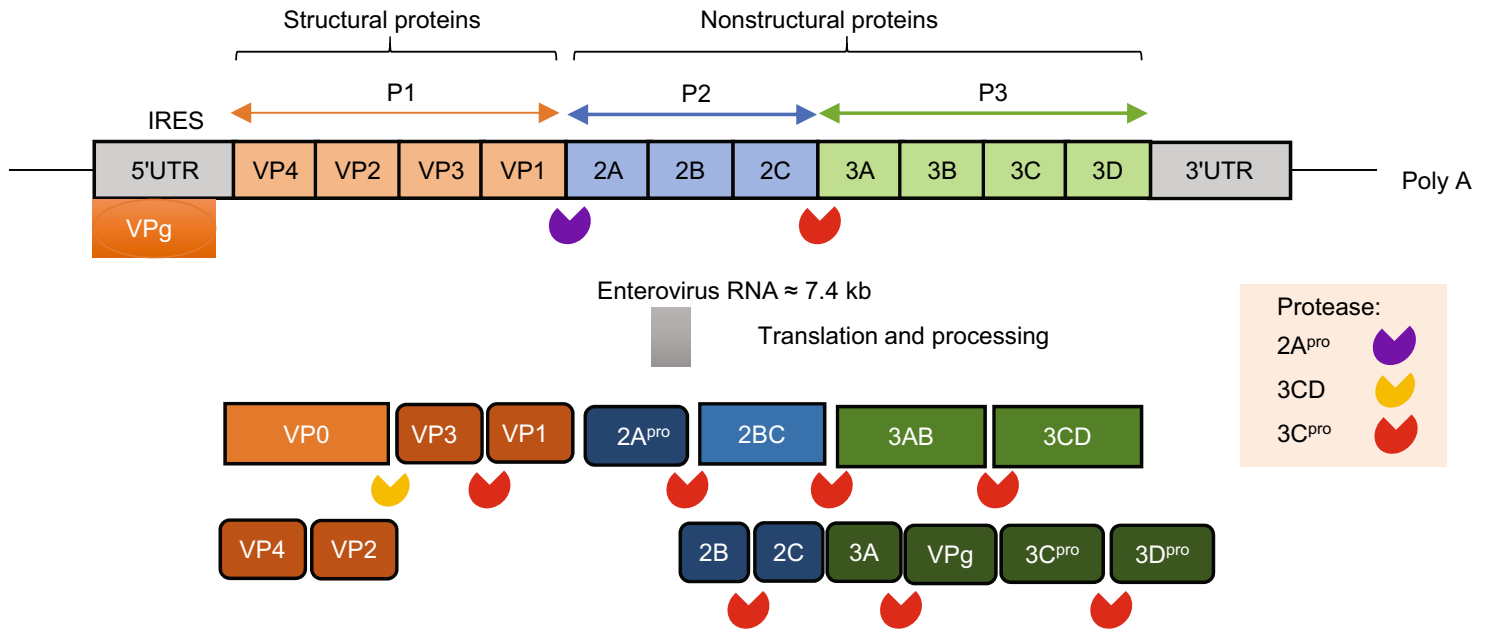

Fig. 1 The structure of enterovirus 71 genome and virion organization. The RNA genome of EV-A71 is approximately $7.4 \mathrm{~kb}$, with an untranslated region (UTR) at the $5^{\prime}$ and $3^{\prime}$ ends of the genome. The $5^{\prime}$ UTR contains an internal ribosomal entry site (IRES) for cap-

protomer. Five protomers come together to form a pentamer, and 12 pentamers plus the viral genome form an icosahedral virion of $\sim 30 \mathrm{~nm}$ diameter (Yi et al. 2017).

\section{Host Immune Responses to Natural Infection of HFMD-Related Viruses}

Humoral immune responses against HFMD-related viruses produce virus-specific neutralizing antibodies, which are generally sufficient to curb virus spreading and makes HFMD a self-limiting disease. However, there were reported cases in infants and young children where severe complications developed despite normal or nearly normal antibody titers compared to patients with mild HFMD, which indicates that other factors contribute to the disease severity (Lim and Poh 2019). The following factors may influence severity: (1) Variation in the IgG composition. The different IgG subclasses that elicited by the viral infection behave differently in virus control. For instance, the $\mathrm{IgG} 1$ subclass, and to a lesser extent the IgG2 subclass, primarily mediate the virus-neutralizing activity, while the IgG3 subclass does not (Cao et al. 2013). (2) Variation in cellular immunity. The circulating virus-specific $\mathrm{CD} 8^{+} \mathrm{T}$ cells and $\mathrm{CD} 4^{+} \mathrm{T}$ cells must be effectively engaged for the timely clearance of virus-infected cells and helping the antibody production (Aw-Yong et al. 2019). (3) Genetic variations. There may be intrinsic differences between individuals in countering a viral invasion due to inherited variations in host factors that determine viral susceptibility at the cellular and organismal levels (Yee and Poh 2018). independent translation. The $5^{\prime} \mathrm{UTR}$ is bound covalently to VPg (3B), and the $3^{\prime}$ UTR includes a poly-A tail. The RNA is translated to a polyprotein that is sequentially cleaved by the viral $2 \mathrm{~A}$ protease (2Apro), 3CD protease, and $3 \mathrm{C}$ protease (3Cpro).

Among the three abovementioned factors, the cellular immune response is the most feasible target for vaccinebased prevention.

\section{Critical Epitopes Recognized by Neutralizing Antibodies}

As components of the virion capsid, VP1, VP2 and VP3 are the main targets of human neutralizing antibodies. VP1 contributes to the majority of neutralizing epitopes, and its binding may be used as a valuable assay to assess vaccine potency. VP2 and VP3 proteins harbor fewer neutralizing epitopes compared to VP1, despite structural similarity. Among the common HFMD-related enteroviruses, EV-A71 and CV-A16 show high conservation in capsid proteins, with approximately $80 \%$ sequence identity, and their neutralizing epitopes are largely overlapped (Anasir and Poh 2019).

The neutralizing epitopes are classified into linear epitopes and conformational epitopes. Most of the linear epitopes are located in the $\mathrm{B}-\mathrm{C}, \mathrm{E}-\mathrm{F}$, and $\mathrm{G}-\mathrm{H}$ loops, and the C-terminus of VP1, the E-F loops of VP2, and $\mathrm{N}$-terminal regions of VP3. CV-A16 also has linear epitopes in the canyon floor of VP1 and the G-H loop of VP3 (Xu et al. 2015; Fang and Liu 2018). Linear neutralizing antigenic sites were also reported in the E-F loop of CV-A10 VP2, in the G-H loop as well as the C-terminus of CV-A6 VP1 (Chen et al. 2018; Dai et al. 2019).The identification of conserved neutralizing linear epitopes provides important targets for the development of multivalent vaccines 
(Xu et al. 2015). For example, MAB979 is an antibody raised by EV-A71 immunization, and it recognized residues 136-150 of VP2 on extensive synthetic peptide screening. It is cross-reactive with CV-A16, but with low neutralizing titers, which indicates a potential epitope for multivalent targeting (Liu C et al. 2011).

The conformational epitopes, which are comprised of amino acids that are discontinuous in sequence but are brought to proximity with three-dimensional protein folding, are more difficult to define compared to linear epitopes, and its ultimate validation may require structural analyses. A number of conformational neutralizing epitopes were identified, and most of these sites were derived from an EV-A71-related study (Fang and Liu 2018). A remarkable example is provided by $\mathrm{mAb} \mathrm{E} 18 / 19$, which are two antibodies generated by immunization with an immature EV-A71 virus. Both antibodies neutralize EV-A71, but via different mechanisms. E18 binds to the virus and causes a conformational change of the bound virus that promotes the release of the viral genome and renders the virus inactivated E19 does not induce genome injection. Structural analyses subsequently revealed that E18 and E19 recognize conformation epitopes on the EV-A71 capsid, but their targets are different. The binding sites of E18 are located between the VP4-VP2-VP3-VP1 protomers, and the E19 sites are exclusively within a single promoter (Plevka et al. 2014). Additional conformational epitopes were identified in other structural features of the capsids of EV-A71, including the five-fold axis, "knob" and G-H loop, canyon northern rim, canyon floor, canyon southern rim, three-fold plateau, and two-fold plateau (Lee et al. 2013; Kiener et al. 2014; Jiang et al. 2015; Arthur Huang et al. 2017; Jia et al. 2017). Studies on CV-A6 indicated that there are also conformational epitopes located in the B-C, E-F, H-I loops of VP1 (Chen et al. 2018; Fang and Liu 2018).

\section{Monovalent Candidates of HFMD Vaccines}

\section{Inactivated Whole Virus Vaccine}

In comparison to other vaccine candidates, inactivated EVA71 vaccines are the only vaccines entering the market. China's Food and Drug Administration (FDA) has issued drug certificates and production licenses for EV-A71 inactivated vaccines from 3 companies, namely, Sinovac, Vigoo, and the Chinese Academy of Medical Sciences (CAMS), all of which are based on C4 subgenotype-the most common genotype in China, although with different virus strain and variation in manufacturing process (Mao et al. 2016) (Table 1). Following successful phase I-III clinical trials, a recent large-scale cohort phase IV study of licensed inactivated EV-A71 vaccine revealed an overall protection effectiveness of $89.7 \%$ against EV-A71 infection along with a $4.58 \%$ rate of reported adverse reaction (Guan et al. 2019). However, both the Sinovac and CAMS EV-A71 vaccines were ineffective for CVA16-associated HFMD, unraveling their genotype specificity (Li et al. 2016; Li R et al. 2014). Besides Chinese mainland, inactivated EV-A71 vaccines were also developed in Taiwan region and Singapore, targeting B3 and B4 subgenotypes respectively. The EV-A71 developed in the Taiwan region has been evaluated in a phase II clinical trials involving a total of 365 infants or children aging from 2 months to 11 years, achieving a seroprotection (neutralization titer $\geq 1: 32$ ) lasting for 2 years in most participants without reported serious adverse events (SAEs) (ClinicalTrials.gov number, NCT02200237). In addition, a cross-reaction was observed against other EV-A71 strain genotypes, including B5, C4a, C4b, and C5 (Huang et al. 2019). A phase III clinical trial has initiated in 2019 and is expected to be completed in 2022 (ClinicalTrials.gov number, NCT03865238) (Lin et al. 2019). Only a small-scale phase I clinical trial has been conducted for EV-A71 vaccine developed in Singapore, and the study claimed that the vaccine induced a high immune response against HFMD caused by EV-A71, although the data has not been publicly disclosed (ClinicalTrials.gov number, NCT01376479). Immunizations with inactivated virions derived from $\mathrm{CV}$ A16, CV-A10 and CV-A6 have been only studied in animal models, and the results provided immunological and functional evidence supporting their efficacy. The generated serum contained high levels of virus-specific neutralizing antibodies, and the serum from immunized mother mice afforded protection against lethal challenges with virulent HFMD-related viruses when it was passively transferred to neonatal mice (Qi An et al. 2014; Zhang et al. 2017a). Therefore, inactivated whole virus vaccine represents the most attainable monovalent HFMD-related vaccine.

\section{Synthetic Peptide and Protein Vaccines}

Synthetic peptide vaccines are usually related to the selected neutralizing epitopes, and the two peptides located in VP1, called SP55 (E-F loop; aa 163-177) and SP70 (G-H loop; aa 208-222) have been shown to elicit EV-A71 specific neutralizing antibodies. SP70 raised a relatively higher titer of neutralizing antibody against EV-A71 than that of SP55. However, the neutralizing antibody titer elicited from the peptide SP70 was just one-fourth of that observed in mice immunized with heat-inactivated EV-A71 (Foo et al. 2007). Thus, given that EV-A71 VP1 peptide or whole protein was only able to raise a neutralizing antibody response generally inferior to that of inactivated EV-A71 vaccines and 
Table 1 Official licensed inactivated EV-A71 vaccines by the Chinese Food and Drug Administration.

\begin{tabular}{llll}
\hline Organizations & Sinovac Biotech Co., Ltd & Beijing Vigoo Biological Co., Ltd & Chinese Academy of Medical Sciences \\
\hline EV-A71 Strain & H07 (C4) & FY (C4) & M01 (C4) \\
Inactivation technique & Formalin & Formalin & Formalin \\
Cell substrate & Vero cells & Vero cells & Human diploid KMB-17 cell \\
Dosages & 400 U, two-dose & 320 U, two-dose & 100 U, two-dose \\
Adjuvant & Aluminum hydroxide & Aluminum hydroxide & Aluminum hydroxide \\
Population target & Children (6-35 month) & Children (6-35 month) & Children (6-71 month) \\
Enrollment & 10,077 & 10,245 & 12,000 \\
References & NCT01507857 & NCT01508247 & NCT01569581 \\
\hline
\end{tabular}

consequently showed a protective effect in animal models limited to a low-dose virus challenge (Premanand et al. 2012), synthetic peptide and protein vaccines have only been tried in the research stage without progression to more commercial development.

\section{Recombinant Subunit Vaccines}

Virus-like particles (VLPs) are a special form of recombinant subunit vaccines for non-enveloped viruses, and can be generated by a number of biosystems. The principle of EV VLPs is to coexpress the genes encoding capsid protein precursor $\mathrm{P} 1$ and protease $3 \mathrm{CD}$, which results in the cleavage of P1 into three capsid subunit proteins VP0, VP1, and VP3 through the action of the 3CD protease. VP0, VP1 and VP3 are subsequently self-assembled into VLPs, which adopt the natural structure of virus capsid and can serve as potential vaccine candidates after purification. VLPs derived from EV-A71, CV-A16, CV-A6 and CV-A10 species were reported to be successfully produced in baculovirus-insect cell (Somasundaram et al. 2016), Pichia pastoris yeast (Zhang et al. 2016) and saccharomyces cerevisiae yeast (Zhao et al. 2013; Zhou et al. 2016; Zhang W et al. 2018). Immunization study in mice showed that VLPs were able to elicit high titers of neutralizing antibodies and afford effective protection against lethal viral challenge (Wang X et al. 2018; Zhou et al. 2018). In addition, a recent study reported that VLP vaccines for HFMD induced a high antigen-specific $B$ cell response that is comparable to inactivated vaccines (Yang et al. 2019) (Table 2). This study produced EV71VLPs in Pichia pastoris, attaining a high expression level of EV71-VLPs greater than $250 \mathrm{mg} / \mathrm{L}$ (Yang et al. 2019). With the higher yield capacity to be more cost effective, EV71VLPs produced in Pichia pastoris are in clinical trial (CXSL1900022), representing a good start toward future commercialization.

\section{Recombinant Virus-Vector Vaccines}

Researchers inserted $P 1$ and $3 C D$ genes of EV-A71 into one vesicular stomatitis virus (VSV) backbone to generate a recombinant VSV to produce VLPs, which protected neonatal mice against lethal viral challenge (Yan et al. 2016). A novel recombinant adenovirus vaccine, Ad-EVVLP, with $P 1$ and $3 C D$ genes of EV-A71 inserted into the adenoviral genome to express VLPs, induced EV-A71specific neutralizing antibodies and Th1/Th2-balanced cellular responses in immunized mice, whereas inactivated EV-A71 vaccine activated only Th2-mediated neutralizing antibody responses to protect against virus challenge (Tsou et al. 2015) (Table 3). The immunogenicity of 71-6 epitope (aa 176-190 of VP3) was tested using the norovirus $\mathrm{P}$ particle as the vaccine carrier, and serum from mice immunized with the resulting chimeric $\mathrm{P}$ particle could protect suckling mice from a lethal dose of EV-A71 infection (Jiang et al. 2015).

\section{Recent Development of Multivalent Vaccines}

Patients with recurrent HFMD are a clear indicator of lack of efficient cross-reactivity among serotypes, informing the need for development of multivalent vaccine. Accordingly, several approaches have been attempted to develop vaccine covering multiple serotypes. The most straightforward approach is simply combining the existing monovalent vaccines into one formulation. There were studies showing that immunization of combined multiserotypic formulations, in the form of either activated virus or VLP, led to effective protection against corresponding viruses without interference, suggesting no cross-serotypic effect. Though simple "mixing" approach does show promise in providing a solution to the issue of multi-protection, it faces the problems of relatively high cost and reliability issue. Consequently, an alternative approach has been also explored utilizing chimeric vaccines generated by engineering vector to co-express viral proteins or peptides from multiple serotypes, generally achieved via partial antigenic substitution and insertion. 
Table 2 The producing systems of enterovirus-related virus-like particle (VLP).

\begin{tabular}{|c|c|c|c|c|}
\hline VLP-producing systems & Yield capacity & Properties & Status & Ref. \\
\hline Baculovirus-insect cell & Moderate $(64.3 \mathrm{mg} / \mathrm{L})$ & $\begin{array}{l}\text { Moderate-yield; Relatively high cost; Large } \\
\text { stocks (cell \& viruses); Contamination } \\
\text { risk of virus }\end{array}$ & Lab & (Chung et al. 2010) \\
\hline $\begin{array}{l}\text { Saccharomyces } \\
\text { cerevisiae yeast }\end{array}$ & Low $(0.25 \mathrm{mg} / \mathrm{L})$ & Low-yield; Low cost; Ease in manipulation & Lab & (Li et al. 2013) \\
\hline Pichia pastoris yeast & High $(270$ mg/L) & High-yield; Low cost; Easy manipulation & $\begin{array}{l}\text { Clinical trial } \\
\quad(\text { CXSL1900022) }\end{array}$ & (Yang et al. 2019) \\
\hline $\begin{array}{l}\text { Recombinant vesicular } \\
\text { stomatitis virus (rVSV) }\end{array}$ & - & $\begin{array}{l}\text { Attenuated }(\Delta \mathrm{M} 51) \text {; } \\
\text { Replication-competent and may have } \\
\text { adverse effects }\end{array}$ & Lab & (Yan et al. 2016) \\
\hline $\begin{array}{l}\text { Recombinant } \\
\text { adenovirus } 5 \text { (Ad-EVVLP) }\end{array}$ & - & $\begin{array}{l}\text { Replication-incompetent }(\Delta \mathrm{E} 1 / \Delta \mathrm{E} 3) \text {; } \\
\text { 3C-specific cellular immunity } \\
\text { Ad-EVVLPs from EV71 genes can } \\
\text { protect against CVA16 infection }\end{array}$ & Lab & (Tsou et al. 2015) \\
\hline
\end{tabular}

Table 3 The characteristics of the primary experimental enterovirus vaccine formats.

\begin{tabular}{|c|c|c|c|c|c|}
\hline $\begin{array}{l}\text { Vaccine } \\
\text { format }\end{array}$ & Conformation & Immunogenicity & $\begin{array}{l}\mathrm{mAb} \\
\text { responses }\end{array}$ & Limitation & Advantages \\
\hline $\begin{array}{l}\text { Inactivated } \\
\text { whole virus }\end{array}$ & $\begin{array}{l}\text { Natural virion with } \\
\text { genome }\end{array}$ & Strong $(+++)$ & $\begin{array}{l}\text { High; } \\
\text { Cross- } \\
\text { genotype } \\
\text { protection }\end{array}$ & Low cross-serotypic protection & Mature technology \\
\hline VLP & $\begin{array}{l}\text { Natural virion } \\
\text { without genome }\end{array}$ & Moderate $(++)$ & $\begin{array}{l}\text { High; } \\
\text { Cross- } \\
\text { genotype } \\
\text { protection }\end{array}$ & Low cross-serotypic protection & $\begin{array}{l}\text { Safe; Low cost; Explicit } \\
\text { composition; Easy large-scale } \\
\text { production and quality } \\
\text { control }\end{array}$ \\
\hline $\begin{array}{l}\text { Synthetic } \\
\text { peptide or } \\
\text { recombinant } \\
\text { subunit }\end{array}$ & $\begin{array}{l}\text { Linear epitope or } \\
\text { antigen }\end{array}$ & $\begin{array}{l}\text { Relatively weak } \\
(+)\end{array}$ & $\begin{array}{l}\text { Low; Cross- } \\
\text { genotype } \\
\text { protection }\end{array}$ & $\begin{array}{l}\text { Low cross-serotypic protection; } \\
\text { Strong adjuvant requirement }\end{array}$ & $\begin{array}{l}\text { Safe; Inexpensive; Explicit } \\
\text { composition; Easy large-scale } \\
\text { production and quality } \\
\text { control }\end{array}$ \\
\hline $\begin{array}{l}\text { Novel } \\
\text { chimeric } \\
\text { vaccines }\end{array}$ & $\begin{array}{l}\text { Natural virion } \\
\text { without genome or } \\
\text { linear epitopes of } \\
\text { antigens }\end{array}$ & $\begin{array}{l}\text { Relatively high } \\
(++/+++)\end{array}$ & $\begin{array}{l}\text { High; } \\
\text { Cross- } \\
\text { genotype } \\
\text { protection }\end{array}$ & $\begin{array}{l}\text { Required to know key } \\
\text { neutralization domain and need } \\
\text { to design the optimal chimeric } \\
\text { strategy }\end{array}$ & $\begin{array}{l}\text { May induce cross-protection of } \\
\text { serotypes }\end{array}$ \\
\hline $\begin{array}{l}\text { Recombinant } \\
\text { virus-vector } \\
\text { vaccines }\end{array}$ & $\begin{array}{l}\text { Natural virion } \\
\text { without genome of } \\
\text { target viruses but } \\
\text { vectors }\end{array}$ & $\begin{array}{l}\text { Relatively high } \\
(++/+++)\end{array}$ & $\begin{array}{l}\text { High; Cross } \\
\text { genotype } \\
\text { protection }\end{array}$ & Risk of vector replication & $\begin{array}{l}\text { May induce cross-protection of } \\
\text { serotypes; Comprehensive } \\
\text { T-cell immune response }\end{array}$ \\
\hline
\end{tabular}

\section{Inactivated Multivalent Vaccines}

Bivalent vaccine approach was first tested on the two major causative agents, EV-A71 and CV-A16. A vaccine formulated by combining inactivated EV-A71 and CV-A16 viruses induced a balanced protective immunity in mice model against EV-A71 and CV-A16 infection without detectable immune interference (Cai et al. 2014). Furthermore, in rhesus macaques model, intradermal immunization of two doses of bivalent EV-A71/CV-A16 inactivated vaccine showed excellent virus containment and protection without immunopathological effect against a subsequent viral challenged with EV-A71 or CV-A16 (Fan et al. 2020). CV-A6 and CV-A10 of the inactivated whole-virus combination vaccines also induce antigenspecific systemic immune responses, which elicit active immunization to achieve a protection rate of $>80 \%$ in controlling homotypic and heterotypic CV-A6 and CVA10 infections (Zhang $\mathrm{Z}$ et al. 2018). A trivalent vaccine candidate containing inactivated EV-A71, CV-A16, and CV-A6 delivered full protection from lethal challenge against EV-A71 and CV-A16, and protection from CV-A6 
challenge was accomplished in a passive transfer study involving serum raised against the trivalent vaccine (Caine et al. 2015). Another inactivated-CV-A6, CV-A10, and CV-A16 trivalent vaccine induced sufficient neutralizing antibodies and cell-mediated immune responses, and there was no sufficient cross-protectivity against heterologous strains (Lim et al. 2018). Collectively, these results indicate that there is no immunological interference between the antigens in their ability to induce virus-specific immune responses, which provides proof-of-concept for multivalent vaccines for broad protection against HFMD.

\section{Multivalent VLPs Vaccines}

A bivalent EV-A71/CV-A16-VLPs vaccine induced a balanced neutralizing antibody response and passively protected mice against EV-A71 and CV-A16 infections (Ku et al. 2014). A tetravalent vaccine, including CV-A10VLP, EV-A71-VLP, CV-A16-VLP, and CV-A6-VLP, elicited antigen-specific and long-lasting serum antibody responses and neutralization titers against EV-A71, CVA16, CV-A10, and CV-A6 strains similar to the monovalent vaccines, which indicates good compatibility among the four antigens in the combination vaccine (Zhang W et al. 2018).

\section{Novel Chimeric Vaccines}

A chimeric EV-A71 virus, in which the VP1 (aa 210-225) epitope was replaced with the epitope of CV-A16, was constructed using a reverse genetics technique to produce an EV-A71/CV-A16 bivalent vaccine candidate (Yang et al. 2016). The other attempt was to replace the EV-A71neutralizing epitope SP70 with the epitope of CV-A16 to form chimeric EV-A71 virus-like particles (ChiEV-A71 VLPs), and immunization with ChiEV-A71 VLPs in mice elicited robust Th1/Th2-dependent immune responses against EV-A71 and CV-A16. Passive immunization with sera raised against ChiEV-A71 VLPs conferred full protection against lethal challenge with EV-A71 and CV-A16 in neonatal mice (Zhao et al. 2015). Structural studies revealed that SP70 epitope replacement converted the surface charge potential of VLP, coupled with variations in amino acid sequences, which most likely accounted for the additional neutralization capability of the ChiEV-A71 VLP. A newly published patent showed that EV-A71 VLP displaying CV-A16 VP1 polypeptides maintained the important neutralizing antibody epitopes of EV-A71 itself, and a CV-A16 VLP displaying EV-A71 VP1 polypeptides elicited a protective neutralizing antibody response directed against EV-A71 and CV-A16 viruses (PCT/MY2017/ 050059-US2019/0224304 A1). Generally, the results above indicate that the substitution and incorporation of key peptides/proteins between serotypes into one construction will be a reasonable method to construct a multivalent HFMD vaccine.

\section{Recombinant Virus-Vector Vaccines}

Bivalent chimeric VLPs presenting SP70 of VP1 and VP2 E-F loop epitopes (aa 141-155) of EV-A71 used the hepatitis B virus core protein $(\mathrm{HBc})$ as a carrier (HBc-E1/2) and induced higher $\operatorname{IgG}$ and neutralization titers against EV-A71 and CV-A16 than immunization with only one epitope incorporated into $\mathrm{HBc}$. More importantly, passive immunization with recombinant $\mathrm{HBc}-\mathrm{E} 2$ particles protected neonatal mice from lethal EV-A71 and CV-A16 infections, and therefore, the VP2 epitope is immunodominant between the two serotypes (Xu et al. 2015). Another bivalent chimeric VLP using the core carrier of a truncated hepatitis B virus (tHBc) displayed conserved epitopes of EV-A71 in SP90 (aa 208-222) of VP1, VP2 (aa 248-263) and CV-A16 in PEP91 (aa 271-285) of VP1, which induced humoral and cellular immune responses and protected neonatal mice born to dams from lethal EV-A71 and partially from CV-A16 infection (Huo et al. 2017). Researchers described a hexon-modified chimpanzee adenovirus serotype 68 (AdC68) bivalent vaccine that incorporated the neutralizing epitope of CV-A16, PEP71, and a shortened neutralizing epitope of EV-A71, sSP70, into the AdC68 hexon, and EV-A71-VP1 was cloned into the E1region of the AdC68 vectors. The candidate elicited neutralizing antibodies against CV-A16 and EV-A71 and conferred protection to suckling mice against a lethal challenge of both viruses, which indicates a potential carrier and epitope-displaying platform (Zhang et al. 2015). Accordingly, the integration of chimeric VLPs into novel virus vectors induced the effect of multivalence, characterized by an enhanced broad systemic immune response.

\section{Experimental Animal Model and Regimen}

Murine and non-primate models are the two major animal models for evaluating HFMD-related vaccines. In mouse model, adult $\mathrm{BALB} / \mathrm{c}$ or ICR mice of 6-8 weeks were routinely selected for immunogenicity assessment. Primeboost represents the most common vaccination strategy with vaccine(s) applied two or three times with an interval of 2-4 weeks via intraperitoneal (i.p.) or intramuscular (i.m.) route (Wang and Yu 2014). Given the HFMD-related viruses only cause minor phenotypes in adult mice, the protective efficacy of experimental vaccines has to be indirectly examined using neonatal mice, which are more susceptible to virus infection than adult mice possibly due 
to their immature immune systems (Yu et al. 2000; Fang and Liu 2018). One-day-old ICR mice infected with EVA71 at a lethal dose of greater than $10^{8} \mathrm{PFU}$ can reach a mortality rate of $100 \%$ following i.p. inoculation (Yu et al. 2000). Neonatal mice infected with the highest dose of CVA16 at $10^{6.5}$ CCID50 had a $100 \%$ mortality by day 6 , and a $100 \%$ mortality by day 13 with the lowest dose at $10^{2.5}$ CCID50 (Li J et al. 2014). CV-A6 and CV-A10 infection murine model have been developed using 5-day-old neonatal mice with $10^{5.5}$ TCID50 viruses via i.m. inoculation (Zhang et al. 2017a, b). Moreover, researchers have generated a transgenic (Tg) mouse expressing hSCARB2, the cellular receptor of EV-A71, which can infect EV-A71 within 1- to 14-day-old at a dose of $3 \times 10^{4}$ to $10^{6} \mathrm{PFU}$ via subcutaneous (s.c.) injection and exhibited neurological disease and pathology very similar to that observed in humans (Yang et al. 2009; Fujii et al. 2013). The vaccine protectiveness is measured by transfusing sera from immunized adult mice to young mice and examining their effect on subsequent viral challenge. An alternative version of this two-step protocol was recently developed by first combining immunized serum with virus in vitro and then applying the neutralization mixture to suckling mice, whereby the time required for the process is greatly shortened (Wang et al. 2016). Gerbil has recently emerged as a new model animal for studying HFMD-related virus as research showed that gerbils up to 21-day-old were fully susceptible to CV-A16 of $10^{5.5}$ TCID50 and this susceptibility, marked by eventual death from neurological disorders, could be achieved on 60-day-old gerbils once the infection dose increased to $10^{8}$ TCID50. Moreover, gerbils up to the age of 14-day-old were also susceptible to CVA10 of $10^{8.5}$ TCID50, with all animals succumbed five days after infection (Sun et al. 2016; Yao et al. 2019; Chen et al. 2020).

The research exploring the non-human primate model of HFMD-related viruses is limited, but the results are promising. In one report, the neonatal rhesus monkeys were challenged with EV-A71 (10 $0^{4.5}$ CCID50/monkey) via intratracheal infection, and HFMD-liked vesicular lesions were found in the mouth and foot, demonstrating the suitability of neonatal non-human primate for dissecting the complete process of EV-A71 infection (Liu L et al. 2011). In another report, upon CV-A16 infection via nasal insufflation, rhesus macaques developed oral mucosa and limb vesicles, a major classical clinical manifestation of HFMD infection. Strikingly, the infected macaques did not elicit CV-A16-specific neutralizing antibodies and functional memory T-cells. Furthermore, transfusion of sera from macaques immunized with inactivated CV-A16 vaccine failed to mount protection against a viral challenge in young macaque recipient. These surprising revelations suggest that the immunological mechanism of CV-A16 infection need to be further investigated (Wang et al. 2017).

\section{Conclusions}

The inactivated EV-A71 vaccines show high efficacy, good immunogenicity persistence and acceptable safety profiles in the vaccination population and efficiently reduce the incidence of HFMD, especially severe cases. However, concerns have risen on changes in dominant HFMDcausing virus strains and emerging new disease-causing serotypes. Therefore, it is imperative to explore multivalent vaccine formulation with broad-spectrum protection and sufficient safety. This exploration would be facilitated by a combinatorial effort involving improved vaccine design and strategy, better utilization of old vaccine vector along with development of new vaccine platforms. Lastly, it will be also helpful to gain a better understanding of how immunological memories develop upon infection with different serotypes, which could serve as an instructive guide for vaccine development.

Acknowledgements This work was sponsored by the National Natural Science Foundation of China (81672018), the National 13th Five-Year Grand Program on Key Infectious Disease Control (2017ZX10202102), the 13th Five-Year National Science and Technology Major Project for infectious Diseases (2017ZX10305501002), Shanghai Pujiang Program (19PJ1409100), the Technology Service Platform for Detecting High level Biological Safety Pathogenic Microorganism Supported by Shanghai Science and Technology Commission (18DZ2293000).

\section{Compliance with Ethical Standards}

Conflict of interest The authors declare that they have no conflict of interest.

Animal and Human Rights Statement This article does not contain any studies with human or animal subjects performed by any of the authors.

\section{References}

Anasir MI, Poh CL (2019) Advances in antigenic peptide-based vaccine and neutralizing antibodies against viruses causing hand, foot, and mouth disease. Int J Mol Sci 20:1256

Arthur Huang KY, Chen MF, Huang YC, Shih SR, Chiu CH, Lin JJ, Wang JR, Tsao KC, Lin TY (2017) Epitope-associated and specificity-focused features of EV71-neutralizing antibody repertoires from plasmablasts of infected children. Nat Commun 8:762

Aw-Yong KL, NikNadia NMN, Tan CW, Sam IC, Chan YF (2019) Immune responses against enterovirus A71 infection: implications for vaccine success. Rev Med Virol 29:e2073

Bian L, Gao F, Mao Q, Sun S, Wu X, Liu S, Yang X, Liang Z (2019) Hand, foot, and mouth disease associated with coxsackievirus 
A10: more serious than it seems. Expert Rev Anti Infect Ther 17:233-242

Cai Y, Ku Z, Liu Q, Leng Q, Huang Z (2014) A combination vaccine comprising of inactivated enterovirus 71 and coxsackievirus A16 elicits balanced protective immunity against both viruses. Vaccine 32:2406-2412

Caine EA, Fuchs J, Das SC, Partidos CD, Osorio JE (2015) Efficacy of a trivalent hand, foot, and mouth disease vaccine against enterovirus 71 and coxsackieviruses A16 and A6 in mice. Viruses 7:5919-5932

Cao RY, Dong DY, Liu RJ, Han JF, Wang GC, Zhao H, Li XF, Deng YQ, Zhu SY, Wang XY, Lin F, Zhang FJ, Chen W, Qin ED, Qin CF (2013) Human IgG Subclasses against Enterovirus Type 71: neutralization versus Antibody Dependent Enhancement of Infection. PLoS ONE 8:e64024

Chen J, Zhang C, Zhou Y, Zhang X, Shen C, Ye X, Jiang W, Huang Z, Cong Y (2018) A 3.0-angstrom resolution cryo-electron microscopy structure and antigenic sites of coxsackievirus A6like particles. J Virol 92:e01257-17

Chen C, Xia Y, Zhu S, Xu F, Sun Y, Lu H, Gao M, Yang Z, Mao Z, Ge Q (2020) Muscle destruction caused by coxsackievirus A10 in gerbils: construction of a novel animal model for antiviral evaluation. Virus Res 286:198067

Chung CY, Chen CY, Lin SY, Chung YC, Chiu HY, Chi WK, Lin YL, Chiang BL, Chen WJ, Hu YC (2010) Enterovirus 71 viruslike particle vaccine: improved production conditions for enhanced yield. Vaccine 28:6951-6957

Dai W, Xiong P, Zhang X, Liu Z, Chen J, Zhou Y, Ye X, Zhang C (2019) Recombinant virus-like particle presenting a newly identified coxsackievirus A10 neutralization epitope induces protective immunity in mice. Antiviral Res 164:139-146

Fan S, Liao Y, Jiang G, Jiang L, Wang L, Xu X, Feng M, Yang E, Zhang Y, Cui W, Li Q (2020) Study of integrated protective immunity induced in rhesus macaques by the intradermal administration of a bivalent EV71-CA16 inactivated vaccine. Vaccine 38:2034-2044

Fang CY, Liu CC (2018) Recent development of enterovirus A vaccine candidates for the prevention of hand, foot, and mouth disease. Expert Rev Vaccines 17:819-831

Foo DGW, Alonso S, Phoon MC, Ramachandran N, Chow VTK, Poh CL (2007) Identification of neutralizing linear epitopes from the VP1 capsid protein of Enterovirus 71 using synthetic peptides. Virus Res 125:61-68

Fujii K, Nagata N, Sato Y, Ong KC, Wong KT, Yamayoshi S, Shimanuki M, Shitara H, Taya C, Koike S (2013) Transgenic mouse model for the study of enterovirus 71 neuropathogenesis. PNAS 110:14753-14758

Guan X, Che Y, Wei S, Li S, Zhao Z, Tong Y, Wang L, Gong W, Zhang Y, Zhao Y (2019) Effectiveness and safety of an inactivated enterovirus 71 vaccine in children aged 6-71 months in a phase IV study. Clin Infect Dis. https://doi.org/10.1093/cid/ ciz1114

Huang LM, Chiu CH, Chiu NC, Lin CY, Li MT, Kuo TY, Weng YJ, Hsieh EF, Tai IC (2019) Immunogenicity, safety, cross-reaction, and immune persistence of an inactivated enterovirus A71 vaccine in children aged from two months to 11 years in Taiwan. Vaccine 37:1827-1835

Huo C, Yang J, Lei L, Qiao L, Xin J, Pan Z (2017) Hepatitis B virus core particles containing multiple epitopes confer protection against enterovirus 71 and coxsackievirus A16 infection in mice. Vaccine 35:7322-7330

Jia Q, Ng Q, Chin W, Meng T, Chow VTK, Wang C-I, Kwang J, He F (2017) Effective in vivo therapeutic IgG antibody against VP3 of enterovirus 71 with receptor-competing activity. Sci Rep $7: 46402$
Jiang L, Fan R, Sun S, Fan P, Su W, Zhou Y, Gao F, Xu F, Kong W, Jiang C (2015) A new EV71 VP3 epitope in norovirus P particle vector displays neutralizing activity and protection in vivo in mice. Vaccine 33:6596-6603

Kiener TK, Jia Q, Meng T, Chow VTK, Kwang J (2014) A novel universal neutralizing monoclonal antibody against enterovirus 71 that targets the highly conserved "knob" region of VP3 protein. PLoS Negl Trop Dis 8:e2895

Ku Z, Liu Q, Ye X, Cai Y, Wang X, Shi J, Li D, Jin X, An W, Huang $Z$ (2014) A virus-like particle based bivalent vaccine confers dual protection against enterovirus 71 and coxsackievirus A16 infections in mice. Vaccine 32:4296-4303

Lee H, Cifuente JO, Ashley RE, Conway JF, Makhov AM, Tano Y, Shimizu H, Nishimura Y, Hafenstein S (2013) A strain-specific epitope of enterovirus 71 identified by cryo-electron microscopy of the complex with fab from neutralizing antibody. J Virol 87:11363-11370

Li HY, Han JF, Qin CF, Chen R (2013) Virus-like particles for enterovirus 71 produced from Saccharomyces cerevisiae potently elicits protective immune responses in mice. Vaccine 31:3281-3287

Li J, Chang J, Liu X, Yang J, Guo H, Wei W, Zhang W, Yu XF (2014) Protection from lethal challenge in a neonatal mouse model by circulating recombinant form coxsackievirus A16 vaccine candidates. J Gen Virol 95:1083

Li R, Liu L, Mo Z, Wang X, Xia J, Liang Z, Zhang Y, Li Y, Mao Q, Wang J, Jiang L, Dong C, Che Y, Huang T, Jiang Z, Xie Z, Wang L, Liao Y, Liang Y, Nong Y, Liu J, Zhao H, Na R, Guo L, Pu J, Yang E, Sun L, Cui P, Shi H, Wang J, Li Q (2014) An inactivated enterovirus 71 vaccine in healthy children. $\mathrm{N}$ Engl $\mathrm{J}$ Med 370:829-837

Li JX, Song YF, Wang L, Zhang XF, Hu YS, Hu YM, Xia JL, Li J, Zhu FC (2016) Two-year efficacy and immunogenicity of Sinovac Enterovirus 71 vaccine against hand, foot and mouth disease in children. Expert Rev Vaccines 15:129-137

Lim HX, Poh CL (2019) Insights into innate and adaptive immune responses in vaccine development against EV-A71. Ther Adv Vaccines Immunother 7:2515135519888998

Lim H, In HJ, Lee JA, Sik Yoo J, Lee SW, Chung GT, Choi YK, Chung JK, Cho SJ, Lee JW (2018) The immunogenicity and protection effect of an inactivated coxsackievirus A6, A10, and A16 vaccine against hand, foot, and mouth disease. Vaccine 36:3445-3452

Lin JY, Kung YA, Shih SR (2019) Antivirals and vaccines for Enterovirus A71. J Biomed Sci 26:65

Liu CC, Chou AH, Lien SP, Lin HY, Liu SJ, Chang JY, Guo MS, Chow YH, Yang WS, Chang KHW, Sia C, Chong P (2011) Identification and characterization of a cross-neutralization epitope of Enterovirus 71. Vaccine 29:4362-4372

Liu L, Zhao H, Zhang Y, Wang J, Che Y, Dong C, Zhang X, Na R, Shi H, Jiang L (2011) Neonatal rhesus monkey is a potential animal model for studying pathogenesis of EV71 infection. Virology 412:91-100

Mao Q, Wang Y, Bian L, Xu M, Liang Z (2016) EV-A71 vaccine licensure: a first step for multivalent enterovirus vaccine to control HFMD and other severe diseases. Emerg Microbes Infect $5: 1-7$

Plevka P, Lim P-Y, Perera R, Cardosa J, Suksatu A, Kuhn RJ, Rossmann MG (2014) Neutralizing antibodies can initiate genome release from human enterovirus 71 . PNAS 111:2134-2139

Premanand B, Kiener TK, Meng T, Tan YR, Jia Q, Chow VT, Kwang $\mathrm{J}$ (2012) Induction of protective immune responses against EV71 in mice by baculovirus encoding a novel expression cassette for capsid protein VP1. Antiviral Res 95:311-315 
Qi An W, Guo SuZ, Wen Pan R, Ping Yang B, Chao Zhang Y, Shi L, Li Q (2014) The immunogenicity and protection effect of the BPL-inactivated CA16 vaccine in different animal systems. Hum Vaccin Immunother 10:628-639

Somasundaram B, Chang C, Fan YY, Lim PY, Cardosa J, Lua L (2016) Characterizing Enterovirus 71 and Coxsackievirus A16 virus-like particles production in insect cells. Methods 95:38-45

Song Y, Zhang Y, Ji T, Gu X, Yang Q, Zhu S, Xu W, Xu Y, Shi Y, Huang X, Li Q, Deng H, Wang X, Yan D, Yu W, Wang S, Yu D, $\mathrm{Xu}$ W (2017) Persistent circulation of Coxsackievirus A6 of genotype D3 in mainland of China between 2008 and 2015. Sci Rep 7:5491

Sun YS, Li YJ, Xia Y, Xu F, Wang WW, Yang ZN, Lu HJ, Chen ZP, Miao ZP, Liang WF, Xu ZY, Dong HJ, Qiu DH, Zhu ZY, van der Veen S, Qian J, Zhou B, Yao PP, Zhu HP (2016) Coxsackievirus A16 induced neurological disorders in young gerbils which could serve as a new animal model for vaccine evaluation. Sci Rep 6:1-11

Tsou YL, Lin YW, Shao HY, Yu SL, Wu SR, Lin HY, Liu CC, Huang C, Chong P, Chow YH (2015) Recombinant adenovaccine expressing enterovirus 71-like particles against hand, foot, and mouth disease. PLoS NTD 9:e0003692

Wang YF, Yu CK (2014) Animal models of enterovirus 71 infection: applications and limitations. J Biomed Sci 21:31

Wang KT, Lin SJ, Wang HC, Chen PC, Lin JJ, Chiang JR, Chang CL, Shih DY, Lo CF, Wang DY (2016) Establishment of an animal challenge model as a potency assay for an inactivated Enterovirus Type 71 vaccine. Biologicals 44:183-190

Wang J, Zhang Y, Zhang X, Hu Y, Dong C, Liu L, Yang E, Che Y, Pu J, Wang X (2017) Pathologic and immunologic characteristics of coxsackievirus A16 infection in rhesus macaques. Virology 500:198-208

Wang J, Teng Z, Cui X, Li C, Pan H, Zheng Y, Mao S, Yang Y, Wu L, Guo X, Zhang X, Zhu Y (2018) Epidemiological and serological surveillance of hand-foot-and-mouth disease in Shanghai, China, 2012-2016. Emerg Microbes Infect 7:8

Wang X, Ku Z, Zhang X, Ye X, Chen J, Liu Q, Zhang W, Zhang C, Fu Z, Jin X, Cong Y, Huang Z (2018) Structure, immunogenicity, and protective mechanism of an Engineered Enterovirus 71-like particle vaccine mimicking $80 \mathrm{~S}$ empty capsid. J Virol 92:e01330-17

Xu L, He D, Yang L, Li Z, Ye X, Yu H, Zhao H, Li S, Yuan L, Qian H, Que Y, Shih JW, Zhu H, Li Y, Cheng T, Xia N (2015) A broadly cross-protective vaccine presenting the neighboring epitopes within the VP1 GH loop and VP2 EF loop of enterovirus 71. Sci Rep 5:12973

Yan Q, Wu L, Chen L, Qin Y, Pan Z, Chen M (2016) Vesicular stomatitis virus-based vaccines expressing EV71 virus-like particles elicit strong immune responses and protect newborn mice from lethal challenges. Vaccine 34:4196-4204

Yang B, Chuang H, Yang KD (2009) Sialylated glycans as receptor and inhibitor of enterovirus 71 infection to DLD-1 intestinal cells. Virol J 6:141

Yang L, Liu Y, Li S, Zhao H, Lin Q, Yu H, Huang X, Zheng Q, Cheng T, Xia N (2016) A novel inactivated enterovirus 71 vaccine can elicit cross-protective immunity against coxsackievirus A16 in mice. Vaccine 34:5938-5945

Yang Z, Gao F, Wang X, Shi L, Zhou Z, Jiang Y, Ma X, Zhang C, Zhou C, Zeng X, Liu G, Fan J, Mao Q, Shi L (2019)
Development and characterization of an enterovirus 71 (EV71) virus-like particles (VLPs) vaccine produced in Pichia pastoris. Hum Vaccin Immunother. https://doi.org/10.1080/21645515. 2019.1649554:1-9

Yao PP, Miao ZP, Xu F, Lu HJ, Sun YS, Xia Y, Chen C, Yang ZN, Xia SC, Jm Jiang (2019) An adult gerbil model for evaluating potential coxsackievirus A16 vaccine candidates. Vaccine 37:5341-5349

Yee PTI, Poh CL (2018) T Cell immunity to enterovirus 71 infection in humans and implications for vaccine development. Int J Med Sci 15:1143

Yi EJ, Shin YJ, Kim JH, Kim TG, Chang SY (2017) Enterovirus 71 infection and vaccines. Clin Exp Vaccine Res 6:4-14

Yu CK, Chen CC, Chen CL, Wang JR, Liu CC, Yan JJ, Su IJ (2000) Neutralizing antibody provided protection against enterovirus type 71 lethal challenge in neonatal mice. J Biomed Sci 7:523-528

Zhang C, Yang Y, Chi Y, Yin J, Yan L, Ku Z, Liu Q, Huang Z, Zhou D (2015) Hexon-modified recombinant E1-deleted adenoviral vectors as bivalent vaccine carriers for Coxsackievirus A16 and Enterovirus 71. Vaccine 33:5087-5094

Zhang C, Liu Q, Ku Z, Hu Y, Ye X, Zhang Y, Huang Z (2016) Coxsackievirus A16-like particles produced in Pichia pastoris elicit high-titer neutralizing antibodies and confer protection against lethal viral challenge in mice. Antiviral Res 129:47-51

Zhang Z, Dong Z, Li J, Carr MJ, Zhuang D, Wang J, Zhang Y, Ding S, Tong Y, Li D (2017a) Protective efficacies of formaldehydeinactivated whole-virus vaccine and antivirals in a murine model of coxsackievirus A10 infection. J Virol 91:e00333-17

Zhang Z, Dong Z, Wei Q, Carr MJ, Li J, Ding S, Tong Y, Li D, Shi W (2017b) A neonatal murine model of coxsackievirus A6 infection for evaluation of antiviral and vaccine efficacy. J Virol 91:e02450-16

Zhang W, Dai W, Zhang C, Zhou Y, Xiong P, Wang S, Ye X, Liu Q, Zhou D, Huang Z (2018) A virus-like particle-based tetravalent vaccine for hand, foot, and mouth disease elicits broad and balanced protective immunity. Emerg Microbes Infect 7:94

Zhang Z, Dong Z, Wang Q, Carr MJ, Li J, Liu T, Li D, Shi W (2018) Characterization of an inactivated whole-virus bivalent vaccine that induces balanced protective immunity against coxsackievirus A6 and A10 in mice. Vaccine 36:7095-7104

Zhao H, Li HY, Han JF, Deng YQ, Li YX, Zhu SY, He YL, Qin ED, Chen R, Qin CF (2013) Virus-like particles produced in Saccharomyces cerevisiae elicit protective immunity against Coxsackievirus A16 in mice. Appl Microbiol Biotechnol 97:10445-10452

Zhao H, Li HY, Han JF, Deng YQ, Zhu SY, Li XF, Yang HQ, Li YX, Zhang Y, Qin ED, Chen R, Qin CF (2015) Novel recombinant chimeric virus-like particle is immunogenic and protective against both enterovirus 71 and coxsackievirus A16 in mice. Sci Rep 5:7878

Zhou Y, Shen C, Zhang C, Zhang W, Wang L, Lan K, Liu Q, Huang Z (2016) Yeast-produced recombinant virus-like particles of coxsackievirus A6 elicited protective antibodies in mice. Antiviral Res 132:165-169

Zhou Y, Zhang C, Liu Q, Gong S, Geng L, Huang Z (2018) A viruslike particle vaccine protects mice against coxsackievirus A10 lethal infection. Antiviral Res 152:124-130 